\title{
Transmission investment problems in Europe: Going beyond standard solutions
}

\author{
Patrik Buijs*, David Bekaert, Stijn Cole, Dirk Van Hertem, Ronnie Belmans \\ Katholieke Universiteit Leuven, Esat-Electa, Kasteelpark Arenberg 10 (PB2445), 3001 Heverlee, Belgium
}

\section{A R T I C L E I N F O}

\section{Article history:}

Received 29 June 2010

Accepted 7 January 2011

\section{Keywords:}

Transmission investments

Transmission technologies

Investment barriers

\begin{abstract}
A B S T R A C T
The European transmission grid is facing an investment challenge. There is a strong call for more transmission capacity. At the same time, the investment climate is fierce and troubled by public opposition, a complex regulatory framework, etc. Many transmission capacity expansion projects are delayed or canceled. In this paper different technology options suitable for increasing transmission capacity are discussed. The aim is to provide policy-makers with information on technologies without going too much into technical details. The focus is on opportunities and limitations to implement various technological alternatives in practice, including technical solutions that go beyond constructing new connection lines. The criteria used in this technology assessment are based on the obstacles reported in the European Priority Interconnection Plan. This ensures a realistic approach based on problems encountered in real projects. Although AC overhead lines $(\mathrm{OHL})$ will remain the standard solution for grid expansion, it is argued that different technology options can overcome many obstacles that OHL face. Additionally, it is illustrated that the higher investment costs for some solutions can be offset with an increased benefit, e.g. by accomplishing investments with smaller delays due to fewer obstacles encountered.
\end{abstract}

(c) 2011 Elsevier Ltd. All rights reserved.

\section{Introduction}

The transmission grid forms the connection between the large generation centers and the load centers across borders. As such, it is essential for a secure supply of electric energy to the customer and enables a sustainable market for electrical energy. It has to keep pace with increase in demand and new generation investments. Investments to maintain and further develop the grid are therefore required. In reality, however, investments are lagging behind during the last decade. Moreover, in the (near) future the grid faces serious challenges, endangering the security of supply and limiting the trade of electric energy. Significant investments in the transmission system are needed.

In 2006, the association of European Transmission System Operators (ETSO, recently transformed to ENTSO-E), stated (ETSO, 2006): "[...] in some countries, not a single overhead power line exceeding five kilometres has been built in the last 10 years." This statement does not take into account underground cables, but at voltages higher than $200 \mathrm{kV}$ the technology has been rarely applied. The Sector Inquiry issued by the European Commission in January 2007 sheds a light on cross-border investments

\footnotetext{
* Corresponding author. Tel.: +32 16 321722; fax: +32 16321985

E-mail address: Patrik.Buijs@esat.kuleuven.be (P. Buijs).
}

(European Commission-DG Competition, 2007). Although crossborder connections are a limited subset of the entire power system and to a certain extent face different (or additional) problems, they can serve as a useful example to illustrate the transmission investment gap. Several borders throughout Europe are often congested, clearly indicating a starving market for interconnection capacity. However, investors are barely tackling this need. The European framework supporting cross-border investments, Trans-European Networks for Energy (TEN-E), gives a similar impression. Although several projects have been identified as priorities already in 1996, many of them are still stuck in a planning phase (European Commission, 1997, 2007a). Recently, the European Commission has put more emphasis on energy infrastructure and the transmission grid in particular (European Commission, 2010a, 2010b). Whereas energy infrastructure rather used to be a side-issue in general European energy policy, it has now come to the foreground and is subject of an explicit energy infrastructure policy. This positive evolution has the potential to better facilitate transmission investments. The new infrastructure package proposes a toolbox aiming at enhanced permitting and financing regional coordination and information dissemination towards the public and decision makers.

Not only are investments developing very slowly, the future need for transmission capacity is increasing. The transmission grid of the (near) future is facing serious challenges. In January 
2008, the European Union has published its ambitious plan for tackling climate change, the so-called 20-20-20 targets. Electricity production from renewable energy sources plays a major role. It is said that about $30 \%$ of electricity production should be provided by renewable energy sources by 2020 . This can only be accomplished by heavily relying on wind energy. Potential wind sites are often located at remote locations. Electrical energy has to be transported towards the load centers. Furthermore, renewable energy sources such as wind energy are notoriously intermittent in their energy output, requiring a stronger transmission system compared to a system with predominantly traditional generators. For instance, in Germany, a leading player with respect to wind energy, the construction of $850 \mathrm{~km}$ of new high voltage lines will be necessary by 2015 according to the DENA grid study of 2005 . This is equivalent with about $5 \%$ of the current German extra high voltage grid (DENA, 2005). According to the more recent followup study DENA II $3600 \mathrm{~km}$ is required by 2020 when using standard technology. Additional investment in temperature monitoring and high-temperature conductors can reduce this number and can reduce the investment burden, but even in such a scenario at least $1700 \mathrm{~km}$ is required (DENA, 2010). Looking at OECD Europe, the International Energy Agency (IEA) estimated in its 2008 World Energy Outlook the required investments in transmission infrastructure for the period 2007-2030 at 187 billion US dollar. Half of this amount should be invested before 2015. An additional 567 billion dollar is estimated as investment need in the distribution grid between 2007 and 2030 (IEA, 2008). A great deal of these investments is related to replacing ageing infrastructure. Large parts of the European grid have been constructed in the decades short after the Second World War up to the 1970s and are near the end of their lifetime.

There are however several obstacles preventing new projects to be developed. ETSO identified a set of barriers impeding new investments in extra high voltage lines: veto powers of involved regions; authorization procedures are too long; too many entities are in charge for delivering permissions and the Environmental Impact Assessment (ETSO, 2006). More concrete are the obstacles identified for specific projects in the Priority Interconnection Plan (PIP) in 2007. Although only cross-border projects are assessed, most of the identified barriers are not related to the cross-border character. Table 1 gives an overview of the PIP obstacles and how many projects out of 32 suffered from them. Most projects encountered obstacles related to the NIMBY phenomenon (obstacles 1-4) (European Commission, 2007b). Section 3 will elaborate further on the issue of investment obstacles. They will be used as a set of criteria to assess the different technology options presented in the paper.

Besides the more concrete obstacles defined above, the regulatory framework a TSO is faced with can result in a reluctance to invest or a delay. A TSO has to experience sufficient incentives

Table 1

Obstacles for PIP projects (based on data in European Commission, 2007b).

\begin{tabular}{llc}
\hline & Obstacle & \# Projects \\
\hline 1 & Electromagnetic fields (EMF) & 11 \\
2 & Environmental issues & 9 \\
3 & Visual impact & 7 \\
4 & Densely populated/urban/rural areas & 7 \\
5 & Grid issues & 9 \\
6 & Dependency on other project(s) & 2 \\
7 & Authorization procedure and legal framework & 12 \\
8 & Identification of cross-border points & 3 \\
9 & Commercial problem & 3 \\
10 & Difficult terrain and weather & 4 \\
11 & No perception of supra-national or European perspective & 2 \\
\hline
\end{tabular}

to invest. Today TSOs are often confronted with pressure from the regulator to keep transmission tariffs low (Meeus et al. 2006). Since the liberalization in Europe took off a decade ago, network tariffs have been the only part of the final electricity price under influence by market authorities and politicians. Keeping tariffs low often implies postponing investments, which has a return only on the short run. Additionally, TSOs are now confronted with more uncertainties in their grid planning compared to the preliberalization era with vertical integrated utilities. Today, information about new generation investments is often not known at the moment transmission investments are planned. Lead times for most types of generation investments are shorter than for transmission (2-5 years versus 10 years). This increased uncertainty gives an incentive to postpone transmission investments until the risk of taking a wrong decision leading to stranded assets is reduced. This type of obstacles related to market design and the bigger context is not further discussed in this paper.

Driven by the past lack of and the massive need for transmission investments, this paper intends to analyze how transmission technology can enable investments. During the last decades several technologies have been developed and matured to the point where they are usable for the transmission of bulk electric power. The transmission business is, however, a sector that slowly adopts new technologies. TSOs are confronted with long asset lifetimes and can therefore be risk averse towards fairly new technologies. Although typical overhead AC lines will remain the standard investment option for the years to come, new technologies are capable of tackling several of the perceived investment barriers and can be considered a suitable replacement, both technically and economically, of the standard AC overhead line.

This viewpoint is supported by the European Network of Transmission System Operators for Electricity (ENTSO-E). In their first publication of the Ten-Year Network Development Plan (TYNDP) for the period 2010-2020, different technologies are discussed and considered as valuable investment options (ENTSO-E, 2010). Several of the concrete projects mentioned in the TYNDP make use of these options. $9600 \mathrm{~km}$ (about 25\% of the total package) comprises new DC lines, mainly undersea. $6800 \mathrm{~km}$ ( $>15 \%$ ) of the existing AC lines is to be refurbished. However, the largest share is taken by 'standard' technology, i.e. 23,200 km (55\%) of new AC OHL at $400 \mathrm{kV}$ is proposed.

The aim of the paper is to provide policy-makers with an overview of the different matured technologies available to tackle the need for more transmission capacity. The focus lies not on a technical discussion of various options but on the applicability and limitations of different technology options. Policy-makers should be able to better adopt a techno-economic viewpoint on how different technologies can contribute. This paper starts with describing the different available technologies indicating their possible contributions and constraints (Section 2). Next, common obstacles encountered in major European investment projects. i.e. the PIP projects, are analyzed and used as a set of criteria to assess the technology options (Section 3). This set of realistic criteria results in a critical appraisal and comparison of the technologies (Section 4). Section 5 concludes the paper.

\section{Technologies}

This paper concentrates on technologies that can enhance the transfer capacity; therefore an overview of different technologies is given. Focus lies on how they can contribute and how they are constrained. A more technical description can be found in Cole et al. (2005).

In investing for the enhancement of the transfer capacity, two approaches can be identified, i.e. building new lines and installing 
devices, which increase the flow through existing assets. The following technologies will be considered:

- installation of AC overhead lines;

- uprating of existing assets;

- installation of underground cables;

- installation of controllable devices (FACTS);

- installation of HVDC lines.

The authors acknowledge technologies such as dynamic line rating, wide area monitoring, etc. These technologies can contribute greatly to the increase in transfer capacity. They can however be cataloged as technologies that enhance 'a more efficient use of existing assets', whereas the scope of this work is focused on hardware investments.

\subsection{Overhead lines}

The traditional approach in transmission system reinforcement is three-phase $A C$ overhead lines $(\mathrm{OHL})$. This solution is very cost effective and robust. It uses technology that is known and used for decades. There are currently no technologies that can compete with OHL when taking only investment cost into account, especially in rural areas (Cigré WG B2.13, 2008). Although OHL often experience short outages, for instance due to lightning strikes, they can be restored with a simple line reclosure, making this a nonissue in meshed transmission systems. However, OHL have a high visual impact and are considered not appealing and possibly hazardous by public opinion. New tower types that are more visually appealing than lattice towers are available, but the towers can still be seen from a (long) distance. Also the electromagnetic fields (EMF) can be reduced, but only to a certain degree. This results in tough siting opposition and long permitting processes. The construction of a new transmission system demands for a new transmission path, which requires a significant right-of-way (a corridor of up to hundreds of meters wide).

OHL technology is well established and much experience has been gained over the years. New developments are the use of fixed insulators, and the use of high temperature conductors and composite materials for the pylons.

\subsection{Uprating of existing circuits}

Uprating is generally understood as increasing the transmission capacity of existing transmission lines. (Cigré WG B2.13, 2008). Adding capacity to existing transmission paths can be done by adding an additional circuit to existing pylons or by increasing the voltage if possible. This is only possible if this uprating was already conceived at the planning stage. If the voltage is increased there has to be taken care of insulation and clearances (both vertical to the ground and internal to other parts of the transmission line). Alternatively, the existing conductors may be replaced by new conductor types with higher ampacity. New materials are constantly developed, which allow higher temperatures, and consequently higher permissible currents for equal cross-sections. Another approach is to look at materials that reduce the sag of a line. Most new developments focus on a tension wire made from a material with a high strength over weight ratio, and a minimum resistance over weight ratio for the conducting material. The use of a composite core as a tension wire is believed to have the highest potential, although it is still under development, and further testing on the highest transmission voltages at the highest capacities is needed.

\subsection{Underground cable connections}

In order to avoid most of the visual impact, undergrounding transmission assets is considered the ideal solution. However, technically and economically this is not necessarily the case. Next to being several times more expensive than $\mathrm{OHL}$, with respect to material cost and installation, high voltage cables for transmission systems act as capacitors, requiring large compensation units and complicating system operations. Cable systems for transmission system voltages are limited in length due to the charging current. Underground cables have been successfully installed in the $400 \mathrm{kV}$ transmission system; however the line length is generally limited to a few kilometers.

A special type of cable is the gas insulated line (GIL), which allows longer lengths, higher transmission voltages and power ratings. The conductor core is placed in an isolating gas within a metal tube. At this moment there are no long distance connections using installed GIL. GIL is more expensive than underground cables.

Serious advances are being made in the field of high temperature superconducting (HTS) cables, which promise high ratings under low losses. At this moment though, the high temperature superconducting technology is not yet ready for use in the transmission system (Exposito et al., 2007). Underground connections are several times more expensive than overhead lines, while less troublesome concerning permitting and social requirements. Therefore, often a compromise solution is found, where part of the connection is overhead and part underground. The combined solution requires a substation at each transition. Each transition also comes with a change in the characteristic impedance, requiring additional equipment to protect it from voltage surges in the transmission system.

Underground connections are frequently installed for lower voltage levels $(\leq 150 \mathrm{kV})$. For higher voltage levels this technology is mainly restricted to short distances, due to high compensation requirements. In Table 2 an overview is given of 380 $400 \mathrm{kV}$ underground connections in Europe. Outside Europe only

Table 2

380-400 kV underground cable connections in Europe (Cigré WG B1.07, 2007).

\begin{tabular}{|c|c|c|c|}
\hline Location & Project name & Cable circuits $\times$ length $(\mathbf{k m})$ & Time period \\
\hline Spain & Barajas Airport (Madrid) & $2 \times 12.8$ & 2004 \\
\hline UK & Elstree-St. Johns Wood & $1 \times 20$ & 2005 \\
\hline UK & Nunthorpe-Newby & $2 \times 5.7$ & 2004 \\
\hline Denmark & Metropolitan power project & $1 \times 12,1 \times 9$ & 1997 \\
\hline Denmark & Metropolitan power project & $1 \times 12$ & 1999 \\
\hline Denmark & Aarhus-Aalborg & $1 \times 2.5,1 \times 4.5,1 \times 7.5$ & 2004 \\
\hline Italy & Turbigo-Rho & $2 \times 8.4$ & 2006 \\
\hline Germany & Berlin diagonal & $1 \times 5.2,1 \times 6.3$ & $1998 / 2000$ \\
\hline Netherlands & N. Waterweg and Calandkanaal crossing & $2 \times 2.25$ & 2005 \\
\hline Austria & Wienstrom & $2 \times 5.2$ & 2005 \\
\hline Germany & Goldisthal pumped storage & $4 \times 0.4$ & 2002 \\
\hline
\end{tabular}


one $500 \mathrm{kV}$ cable of $39.8 \mathrm{~km}$ in Japan and several installations comparable with the European cases are reported (Cigré WG B1.07, 2007).

\subsection{Flexible AC transmission systems (FACTS) or power flow controlling devices}

FACTS is a generic term for installations, which allows to control the power flow. Therefore they are sometimes called power flow controlling devices (PFC). In contrast with the solutions proposed above all add capacity by adding new paths or strengthening existing paths. PFCs offer a completely different approach as they consist of devices placed at a specific point in the grid. As such they can be connected to existing lines, influencing the flow through that line. The additional space required is limited; they can be placed in an existing substation. This makes the permitting process relatively straightforward. Controlling the power flow, PFCs can redistribute the line flows in the system, alleviating stress on the heavily loaded lines, and thus increasing the overall transfer capabilities of the grid. As this technology presents a single investment in a single device, the solution is relatively cheap compared to other ones. PFCs receive lots of attention of TSOs that are looking for increased transmission capacity without actually having to build new lines.

Distinction has to be made between different types of controllable devices. The technology used for the construction of power flow controlling devices can be divided into three main categories, based on their switching method:

- mechanically switched;

- thyristor controlled switching;

- fast switching, power electronic converter based.

The main difference between these technologies is speed. Mechanical switches, such as mechanical tap changers, are used for phase shifting transformers which can be used for regulating steady-state power flow, but are too slow to provide additional dynamic control. The phase shifting transformer can set the power flow through a transmission line, avoiding unidentified loop flows and sharing the power flow over parallel lines. Transformers equipped with tap changers and phase shifting transformers are very efficient, reliable, installed all over the world and are well known by TSOs (Van Hertem, 2009; Van Hertem et al., 2005).

Thyristor based controllers can switch much faster, typically within a few periods of the system frequency. A lot of these devices are installed, mainly Static Var Compensators (SVC) and HVDC systems. Fast switching valves, e.g. Insulated Gate Bipolar Transistors (IGBTs), allow a straightforward construction of voltage source converters (VSC), making practically instant control possible. A growing experience and new developments in power electronics (such as silicon-carbide, gallium-nitride and synthetic diamond) are promising to reduce price and lower losses on the long run. Both thyristor based and IGBT based controllable devices can provide additional dynamic control and damping to the power system, increasing the security and loadability of the power system.

New power lines change the transmission system and its impedances in a discrete manner. Consequently, the power flows in the system change also in a discrete manner. In the case of power flow controllers, making use of the flexibility inherent to the power flow controllers, the flows can be altered in a continuous manner. This gives the system operator the ability to gradually influence the grid parameters to optimally tune it towards a chosen optimum, such as minimal losses, maximum
Table 3

Limits of HVDC systems (Cole et al., 2009).

\begin{tabular}{llc}
\hline & LCC HVDC & VSC HVDC \\
\hline & \multicolumn{2}{c}{ State-of-the-art: } \\
Transmission capacity $(\mathrm{MW})$ & 6300 & 350 \\
Voltage $\left(U_{\mathrm{DC}}\right)(\mathrm{kV})$ & \pm 600 & \pm 150 \\
& State-of-the-art: possible \\
Transmission capacity $(\mathrm{MW})$ & 6400 & 1100 \\
Voltage $\left(U_{\mathrm{DC}}\right)(\mathrm{kV})$ & \pm 800 & \pm 300 \\
\hline
\end{tabular}

transmission capacity towards a certain neighbor, maximum security margin or a combination of these. Power flow controlling devices allow to dynamically change the grid configuration based on external factors such as change in market patterns, without the need to curtail power transactions and while keeping the grid secure.

\section{5. $H V D C$}

An alternative way of providing additional transmission capacity is the installation of an HVDC link. An HVDC system consists of a rectifier, a DC conductor and an inverter. DC links are mainly used for transportation of bulk power over long distances, or for undersea transmission. DC conductors have lower losses per kilometer than AC conductors. However, the converters exhibit high losses. There exists a certain distance, the break-even distance, where the losses of an AC line are equal to the losses of the HVDC system. For distances longer than the break-even distance, HVDC systems have lower losses than AC lines. For undersea connections, HVDC cables are used. AC cables would require reactive compensation at regular intervals, which is very impractical at sea. Line commutated converter (LCC) HVDC systems use thyristor valves. They thus inherit the advantages in terms of power flow control of thyristor based FACTS. A new development in HVDC systems is the voltage source converter (VSC) HVDC. This new technology has some important advantages over LCC HVDC. While the latter can only control active power, the former can control both active and reactive power, which is advantageous for grid operation. The ability to control reactive power means that no external reactive power sources have to be connected to the converter. With LCC HVDC, bulky reactive filters are needed. Therefore, VSC HVDC has a much smaller footprint. Its drawbacks compared to LCC HVDC are the higher losses and lower power and voltage ratings. In Table 3 the ratings for HVDC systems are given.

The number of network elements with VSCs in the transmission grid is currently very limited. However, they offer the most possibilities and are likely to become attractive when several grid issues disallow conventional $A C$ and would require a combination of FACTS. An example is LCC HVDC in weak networks. There is an extensive literature discussing problems of LCC HVDC in weak networks. They are prone to commutation failures and voltage instability and have to be supported by additional FACTS such as SVCs. A VSC converter can operate in weak networks without the need for additional FACTS.

\section{Comparison of technologies according to the identified obstacles}

Of the 11 obstacles mentioned in Table 1,8 will be discussed here. We focus on those obstacles that can be possibly overcome using a different transmission technology. First comes 'EMF', a serious obstacle identified in the PIP projects. 'Environmental 
issues', 'visual impact' and 'densely populated/urban/rural areas' are covered together in the following section, followed by 'grid issues' and 'dependency on other project(s)'. Lastly 'authorization procedure and legal framework' is thoroughly discussed. 'Commercial problem' is not specifically dealt with, but in the previous section on technologies and in the evaluation the cost sides are briefly discussed. 'No perception of supra-national or European perspective' is considered to be technology independent. 'Identification of cross-border points' is too project specific and is not further discussed.

\subsection{Electromagnetic fields (EMF)}

With 11 projects identifying electromagnetic fields (EMF) as an obstacle, EMF are clearly a major concern for the public. Up to now health risks of oscillating low frequency magnetic fields are not scientifically proven. The uncertainty is not due to a lack of scientific sound studies, but rather to the difficulties involved in proving or disproving a causal relationship between electromagnetic fields and health effects. In recommendation 1999/519/EC (Council of the European Union, 1999) the Council of the European Union restricts exposure of the general public (as opposed to working staff) to extremely low frequency EMF, in accordance with recommendations of the International Commission on NonIonizing Radiation Protection (ICNIRP). Some countries have chosen levels deviating from the European recommendation. Eurelectric has given an overview of the different restrictions in and outside Europe (Eurelectric, 2006).

It is uncertain whether the public concern towards EMF would reduce even if scientific studies would prove that the effect of EMF exposure is negligible. The fact that overhead transmission lines are visually very striking strengthens the averse feeling towards overhead lines and the believe that this equipment has an influence on the public health. Measures to reduce the impact of EMF from overhead lines are possible, such as elevation of the lines, transposition of the phases, splitting the phases, and using horizontal instead of vertical isolators.

Underground cables are perceived as less problematic by the public as they are buried and thus out of sight. While it is true that the spread of the magnetic fields caused by cables is smaller, the maximum level of the field is actually much higher than for overhead lines. Also for underground cables, there exist methods to reduce the EMFs, such as arrangement of the conductors in trefoil configuration, phase transposition, the use of passive compensation circuits and metallic shielding. Measures to reduce EMF, both for cable and OHL, do have a profound impact on the project costs.

GILs result in much smaller electromagnetic fields than conventional power transmission systems. For a $400 \mathrm{kV}$ double circuit system with $2 \times 1000$ MVA flow, the magnetic field is about 100 times smaller than the European recommendation. HVDC cables have no oscillating low frequency field, as the frequency is zero. The fields of HVDC cables are thus, contrary to AC lines or cables, static. This static field in close proximity to the transmission line is approximately one-third of the average earth magnetic field and is therefore to believed to represent no health risk.

\subsection{Grid issues and dependency on other projects}

According to Table 1, nine projects mention 'grid issues' as an obstacle. Grid issues refer to a variety of technical problems such as difficulty to connect to weak grids, impact of wind energy, increased loop flows and problems with grid stability. When considering new connections, a full technical feasibility study should be performed. Especially in weak grids, new AC connections may necessitate additional investments to reinforce the grid and ensure its secure operation. AC connections cannot control the power flow: the power flows are distributed according to the line impedances, which inevitably leads to loop flows.

Flexible grid elements such as FACTS and HVDC offer means to control the power system in steady-state and dynamically. In steady-state, they can provide voltage regulation, power flow control, congestion management, etc. Dynamically, FACTS can provide fast voltage support, power oscillation damping, voltage stability support, etc. (Zhang et al. 2005).

\subsection{Environmental issues}

When planning the construction of a new transmission line, several environmental aspects have to be taken into account, such as impact on vegetation, land use and devaluation of esthetic value of protected natural sites and landscapes. The growing awareness of the importance of sustainable development becomes an ever more prominent factor in the power industry. As the environmental aspects become more important, the classic approach to network reinforcement, i.e. the construction of $A C$ overhead lines, faces even tougher public opposition. Of prime concern is the high visual impact of overhead lines running through landscapes and near residential areas (and the related depreciation of real-estate). Undergrounding the lines is an obvious solution. Already in the early 1970s, The Netherlands concluded that a network based on underground cable systems was the answer to many environmental issues. The entire low and medium voltage network of the Netherlands is therefore undergrounded (European Commission, 2003). Concerning the high and extra high voltage grid, only a small percentage of the network is underground, although environmental and visual impact of the extra high voltage grid is the highest. This is partly due to economic considerations, but mainly due to technical problems related to underground $A C$ cables at very high voltages.

HVDC systems can operate with overhead or underground conductors. In Europe, HVDC links are predominantly undersea, with only a few short connections from the sea cable to the converter station overhead. When overhead DC lines are used, the right-of-way is much smaller than for AC, especially for high power ratings. A drawback of HVDC, however, is the need for large converter stations at both ends of the line. Noise and visual impact are the main environmental aspects related to converter stations. However, environmental impact is localized and poses no difficulties, provided the converter stations are not located near residential areas or valuable natural landscape. VSC HVDC converter stations have a considerably smaller footprint than conventional HVDC converter stations, which can have a footprint of several hectares. The environmental impact of FACTS is minor as they can be conveniently installed in substations.

\subsection{Authorization procedure and legal framework}

According to Table 1, in 12 out of 32 PIP-projects the authorization procedure and legal framework is experienced as an investment obstacle. Several reasons can be identified and can sometimes be indirectly linked to the previously discussed obstacles. The non-harmonized cross-border framework, a disproportionate impact of different decision levels on a project acceptance and badly designed procedures often are the core of project delays. These project delays can partly be decreased by opting for a suitable technology and avoiding some obstacles in the earliest stages of the project. This can even yield an economic benefit. Although an adequate technology choice might indeed 
solve some problems, legislators should be aware of their impact and carefully analyze any attempt to bias investors to the 'right' technology.

\subsubsection{Reasons underlying failing procedures and legal frameworks}

Firstly, there is a problem of convincing the public of the usefulness of a project. This is especially the case for the extra high voltage grid that serves an entire zone or country and not just a limited set of local municipalities hosting the new investment and possibly suffering from visual impact, EMF, etc. This phenomenon can result in fierce local opposition and end up in a long approval period with several appeals and amendments to the project. In some cases, it might even kill a project. Whereas the local aspects should not be neglected and proper measures should be taken to minimize the inconvenience or even to arrange a form of compensation, the local influence in projects of national or even international importance has to be carefully managed. The problem of local veto powers is acknowledged by ETSO (ETSO, 2006). For instance, in the US, as a solution the Federal Energy Regulatory Commission (FERC) is in some circumstances allowed to overrule state permitting decisions in order to foster transmission projects within 'national interest electric transmission corridors' (US Congress, 2005).

Secondly, procedures can be badly designed, i.e. they inherently tend to result in long delays. This is for instance the case when procedures have an open end and possibilities for appeal or amendments are not limited in time. When different competent authorities are involved the administrative process and requirements should be tuned to each other. As already noted in the introduction, ETSO identified several difficulties related to this issue, such as the number of competent authorities involved in permitting and the environmental impact assessment (ETSO, 2006).

A third reason specifically holds for cross-border projects, like many of the PIP projects. A lack of harmonization of procedures and technical requirements (e.g. line temperature limits) causes delays and increases complexity.

\subsubsection{The extra benefit of choosing a suitable technology}

Choosing one technology usually implies excluding alternative technologies. Choosing between mutually exclusive options creates an opportunity cost. In cost comparisons between different technologies, this aspect is often ignored. Cost-benefit analyses often include only the investment and maintenance costs. Costs or benefits to society are not always accounted for. From the above discussion it is clear that some technologies face fewer obstacles than others. The result can be that a project can be finished earlier because, for instance, the permits are more easily obtained. One can, for instance, expect to meet less public opposition in case of an underground cable compared to an overhead solution resulting in fewer appeals, veto rights being used, etc. When investments are realized faster, society can reap its benefits faster. This time aspect is often neglected, but should be incorporated in the cost-benefit analysis when social welfare is maximized. For instance, the transmission license holders in the UK conducted a study in which they explicitly took this effect into account and acknowledged the fact that technology choice can impact the duration of the permitting process. In this context HVDC, series compensation and subsea connections are mentioned (Electricity Strategy Networks Group, 2009).

In order to illustrate the effect, a stylized example is constructed. Assume an investment in an overhead line with an investment cost of $75 \mathrm{M} €$. A regular lead time of 5 years, i.e. the lead that would occur in case of no obstacles, is assumed. When due to different obstacles the actual lead time would be 10 or 15

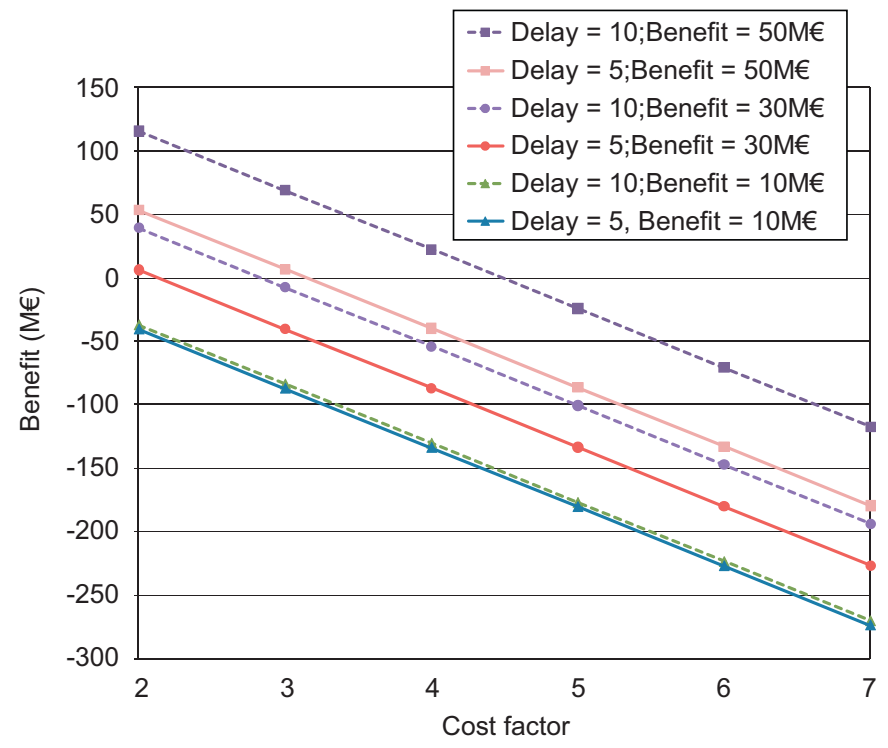

Fig. 1. The effect of completing investments earlier using alternative technologies in order to capture benefits sooner for different cost factors.

years, Fig. 1 illustrates the benefit of achieving the regular lead time of 5 years using a more expensive technology. Cost factors of 2-7 are applied. The yearly benefit of having the investment in place varies from 10 to $50 \mathrm{M} €$ per year. A discount rate of $6 \%$ is used. When, for instance, the yearly benefits from the investment can be assumed to be $50 \mathrm{M} €$ in combination with accomplishing the investment 10 years sooner than the standard solution and a cost factor of 3, a total benefit of $69 \mathrm{M} €$ is obtained (Fig. 1).

The values used to calibrate the example are reasonable. With respect to the OHL investment, PIP reports similar costs for several projects. The cost factor range is wide. This allows taking into account less expensive technologies not requiring new rights of ways (it can even be argued that they are sometimes cheaper than OHL, but such example is not displayed in the graph) and investments in completely new lines. Estimating the benefits of an investment is not straightforward. In a study of 2005 conducted by KEMA a yearly estimate of the surplus is calculated based on the improved economic efficiency of the generation dispatch of investments of interconnectors in the European Union accession countries. It is analyzed how cheap generation can replace more expensive generation by having a transmission project done. Although the values will be different, the applied reasoning also holds for other technologies and for transmission investments within one zone. Several of the studied investments are also on the PIP list. For instance, a $1000 \mathrm{MW}$ link between Poland and Lithuania would save $48.3 \mathrm{M} €$ per year according to the KEMA estimate. For other investments, the benefits have the same order of magnitude (KEMA Consulting, 2005). Another approach to the potential benefit is looking at current congestion revenues; although congestion revenues are no exact match to congestion costs, they can be used to check the order of magnitude of the values reported of KEMA. Data published by the European Commission confirm this (European Commission, 2009).

Fig. 1 shows that when benefits are sufficiently high and the sooner the investment can be done compared to OHL, the higher the benefit of using an alternative technology. A higher cost factor obviously decreases the benefit. In a lot of cases a negative benefit occurs. At first sight this suggests that it is not worth opting for an alternative technology. However, the example does only take into account the mere investment cost and the economic benefit of the investment. The true social cost of the investment is not 
accounted for. For instance, the benefits from not having visual impact, less EMF, higher reliability, etc. are not quantified. In terms of Fig. 1, if the assumed cost factor equals 4 and in case of $50 \mathrm{M} €$ yearly benefit and a delay of 5 years in case of the standard solution, the total benefits from avoiding visual impact, EMF etc. should at least equal $40 \mathrm{M} €$ to compensate the extra cost of taking an alternative technology. These benefits should also be taken into consideration and they can positively affect the analysis, i.e. it could imply a shift to a higher curve in Fig. 1. Quantifying these benefits is extremely difficult and goes beyond the scope of this paper.

\subsubsection{Impact of the legislator}

Taking into account the reasons underlying local opposition and the benefits society can gain by a timely project implementation, legislators can issue proactive regulation. Doing so they can bias the technology choice towards more acceptable technologies. As such, the idea can be worthwhile. However, the impact of such regulation should be carefully assessed.

There are several examples of such regulation. As discussed above, exposure to EMF is strongly regulated by the European authorities and countries can even go further and impose stronger restrictions. Secondly, The 'Erdkabelgesetz' of Lower Saxony (Germany) of 2007 stipulates that transmission lines ( $\geq 110 \mathrm{kV}$ ) have to be undergrounded in the neighborhood of populated areas. Distances of $400 \mathrm{~m}$ from a residential area and $200 \mathrm{~m}$ from a single house have to be kept by overhead lines; otherwise underground solutions have to be used (Landtag, 2007). As a third example, the Danish idea of undergrounding significant parts of the high-voltage grid goes even further. Not only new, but also the existing $132-150 \mathrm{kV}$ connections have to be put underground in this national cable action plan (Energinet.dk, 2008). The above examples can deliver good and acceptable results, but one should be careful by eliminating some technologies beforehand. In some cases other solutions, such as compensating negatively affected parties, can be adequate and from a cost-benefit point of view more rewarding.

\section{Evaluation}

The first five rows of Table 4 list the most important obstacles identified in the PIP projects and discussed in Sections 1 and 3. The technologies from Section 2 make out the different columns of the table.

Due to the fundamental difference between the EMF of cables and overhead lines, the obstacle EMF has been subdivided in peak value and spread of the EMF. Cables score much better on the spread compared with AC overhead lines, but have higher peak values. DC systems exhibit no oscillating field, and are considered safer with respect to EMF. The impact of uprating on EMF cannot be generalized. While the aim of uprating is to increase the ampacity of the conductors, which causes higher magnetic fields and structural changes, such as an increase in tower height or a different insulator configuration, often necessary to achieve higher ampacities, can be beneficial to EMF. Conversely, such structural changes to the towers negatively impact the visual discomfort caused by overhead lines. On the other hand, it can be argued that uprating a line renders the construction of new lines superfluous, at least for a certain time, thus positively impacting visual discomfort.

According to Table 4, the score of all technologies but AC overhead lines on authorization procedure and legal framework is positive. A positive result is explained by the fact that these technologies have characteristics that are favorable for accomplishing procedures in due time. There is a clear link with other criteria like visual impact, EMF reduction, etc. Of course, some general problems with procedures and legislation are not solved by opting for a different technology.

FACTS and HVDC have a positive effect on grid stability and loop flows, which renders a positive score on grid issues. This is even more true for fast acting FACTS and HVDC.

From this table it can be clearly seen that other technologies can overcome obstacles projects are facing when considering AC overhead lines. The balance is so overwhelmingly negative for AC overhead lines, that one can question the viability of this option altogether. The answer can be partly found in the last two rows of the table. Firstly, the ability of each technology to transport sufficiently high amounts of power is evaluated. Secondly, the capability of applying a technology over longer distance is assessed. Conventional AC overhead lines experience no problems whatsoever, except in the most extreme cases where many GWs of power have to be transported over hundreds of kilometers. In this case, (LCC) HVDC is the preferred technical and economic option. AC cables on the other hand, need reactive compensation at long distances as well as many joints, the weakest link of cable systems. The length criterion is not applicable to FACTS that are located in substations. FACTS and uprating can only provide limited capacity increase. While they may have several benefits, it must be borne in mind that they may necessitate additional investments in future.

\section{Conclusion}

Developing new transmission lines in Europe is a harsh challenge today. Despite the growing need for more investments it has never been more difficult to construct new lines. The PIP serves as a good illustration of the struggle for transmission investment projects and the delays encountered. The observed obstacles for these projects cover a wide range of problems. In this paper the transmission investment problem is tackled from this angle, i.e. starting from today's obstacles in bringing new investments to the market different technologies are analyzed upon their merits for coping with these specific obstacles. Within this context, this paper's analysis should allow policy-makers to better assess the merits of alternative technologies.

EMF and environmental concerns, grid issues, authorization procedures and the legal framework create the most problems in

Table 4

Evaluation of technologies.

\begin{tabular}{|c|c|c|c|c|c|c|}
\hline & & $\mathrm{AC} \mathrm{OHL}$ & Uprating & AC cable & PFC & HVDC \\
\hline \multirow[t]{2}{*}{ EMF } & Peak-value & + & \pm & - & + & ++ \\
\hline & Corridor & - & \pm & + & + & ++ \\
\hline \multicolumn{2}{|c|}{ Environment, visual impact, densely populated areas } & -- & \pm & + & ++ & + \\
\hline \multicolumn{2}{|c|}{ Grid issues } & - & - & -- & $+1++($ VSC $)$ & $+1++(\mathrm{VSC})$ \\
\hline \multicolumn{2}{|c|}{ Additional capacity } & ++ & - & + & - & $++1+($ VSC $)$ \\
\hline \multicolumn{2}{|c|}{ Length } & + & + & - & NA & ++ \\
\hline
\end{tabular}


the PIP projects. EMF and environmental concerns often result in public opposition to new investments. This can result in more lengthy authorization procedures. These procedures and the legal framework are often flawed and not streamlined. Delays of several years are not uncommon. Improving the legal framework and the procedures can already improve the situation. Choosing an appropriate technology is another route to follow.

In this paper the merits of different technologies with respect to the observed obstacles are discussed. In general, and also in the PIP projects, the use of AC overhead lines is the most common solution when investments are required. The uprating of existing lines, using $\mathrm{AC}$ cables, installing power flow controlling devices and using underground HVDC links can be used to tackle some of the obstacles encountered with AC overhead lines.

Although some technologies, for instance, power flow controlling devices and HVDC, are clearly able to outperform AC overhead lines for the discussed criteria, this does not imply that it is always possible or even desirable to use these technologies. Power flow controlling devices can only be installed on existing lines. The same is true for uprating technologies. The extra transmission capacity created by these investments is only incremental compared to new AC lines. In some cases this will not be sufficient. HVDC also has clear benefits, especially when VSC technology is used. But today VSC HVDC is only available for smaller capacities. AC cables at extra high voltages $(400 \mathrm{kV})$ are not common, especially not for long distances. Additionally, investment costs are not explicitly discussed in this paper, but should be carefully considered. A more expensive technology can sometimes help in reducing the lead time, but a careful costbenefit analysis should be done. AC overhead lines have the benefit of being a well known and cheap technology when distances are not extreme.

In conclusion, in the current context of a harsh investment climate with multiple obstacles, the increased awareness of different technologies has to be supported. Their applicability, but also their limitations, should be carefully considered in any investment analysis. Like advocated for in the TYNDP, investors should have an open mind and not restrict themselves to the typical AC overhead lines and assess other technology options from the beginning. Each project is different and there is not a single perfect solution, but different technologies are available and viable. Although this can sometimes imply a higher installation or operational cost, the impact on public opposition and eventually the project lead time can change the cost-benefit balance.

\section{References}

Cigré WG B1.07, 2007. Statistics of AC underground cables in power networks, Cigré Technical Brochure.

Cigré WG B2.13, 2008. Guidelines for increased utilization of existing overhead transmission lines, Cigré Technical Brochure.

Cole, S., Belmans, R., 2009. High voltage direct current: from large-scale power transmission to flexible transmission systems. IEEE Industrial Electronics Magazine, September 2009, pp. 19-24.
Cole, S., Van Hertem, D., Meeus, L., Belmans, R., 2005. Technical developments for the future transmission grid. In: Proceedings of the International Conference on Future Power Systems, Amsterdam, the Netherlands.

Council of the European Union, 1999. Council Recommendation of 12 July 1999 on the limitation of exposure of the general public to electromagnetic fields (0-300 GHz) (1999/519/EC).

Deutsche Energie-Agentur (DENA), 2005. Planning of the grid integration of wind energy in Germany onshore and offshore up to the year 2020 (Dena Grid study), English Summary.

Deutsche Energie-Agentur (DENA), 2010. dena-Netzstudie II-Integration erneuerbarer Energien in die deutsche Stromversorgung im Zeitraum 2015-2020 mit Ausblick 2025, Zusammenfassung.

Electricity Networks Strategy Group, 2009. Our Electricity Transmission Network: A Vision for 2020, Full Report. Online available at: <http://www.ensg.gov.uk/ assets/ensg transmission_pwg full_report final issue 1.pdf $\rangle$.

Energinet.dk, 2008. More undergrounding in power system expansion. News article, 5 November 2008. Online available at: http://www.energinet.dk/en/ menu/News/News/News.htm.

Eurelectric, 2006. EMF exposure standards applicable in Europe and elsewhereEnvironment \& Society Working Group. Ref: 2006-450-0006.

European Commission - DG Competition, 2007. Report on the energy sector inquiry, Part 2, SEC(2006)1724.

European Commission, 1997. Trans-European energy networks: policy and actions of the EC.

European Commission, 2003. Undergrounding of electricity lines in Europe. Background paper, Brussels, Belgium.

European Commission, 2007a. Inquiry pursuant to Article 17 of Regulation (EC) no 1/2003 into the European gas and electricity sectors (final report)-priority interconnection plan.

European Commission, 2007b. Inquiry pursuant to Article 17 of Regulation (EC) no $1 / 2003$ into the European gas and electricity sectors (final report) - priority interconnection plan - Annex.

European Commission, 2009. Table congestion revenues. Online available at: 〈http://ec.europa.eu/energy/gas_electricity/consultations/doc/2009_02_28_ tso_revenues.pdf $\rangle$.

European Commission, 2010a, Energy 2020A strategy for competitive, sustainable and secure energy, $\operatorname{COM}(2010) 639$ final, Brussels, November 2010.

European Commission, 2010b, Energy infrastructure priorities for 2020 and beyond-a blueprint for an integrated European energy network, $\operatorname{COM}(2010) 677$ final, Brussels, November 2010.

European Network of Transmission Operators for Electricity (ENTSO-E), 2010. Tenyear network development plan 2010-2020. Available at: http://www.entsoe. eu/index.php?id=232.

European Transmission System Operators (ETSO), 2006. Overview of the administrative procedures for constructing $110 \mathrm{kV}$ to $400 \mathrm{kV}$ overhead lines.

Exposito, A.G., Santos, J.R., Cruz Romero, P., 2007. Planning and operational issues arising from the widespread use of HTLS conductors. IEEE Transactions on Power Systems 22 (4), 1446-1455.

International Energy Agency (IEA), 2008. World Energy Outlook 2008, Paris, France.

KEMA Consulting, 2005. Analysis of the network capacities and possible congestion of the electricity transmission networks within the accession countries. Report prepared for European Commission DG TREN, Bonn, Germany.

Meeus, L., Purchala, K., Van Hertem, D., Belmans, R., 2006. Regulated cross-border transmission investment in Europe. European Transactions on Electrical Power 16 (6), 591-601.

Niedersächsische Landtag, 2007. Niedersächsisches Erdkabelgesetz, Nds.GVBl. Nr.40/ 2007S.709. Online available at: 〈http://www.netzausbauniedersachsen.de/ 00000099a20f0ea04/00000099b50b79201/index.html >.

US Congress, 2005. Energy Policy Act of 2005, H.R. 6, 109 Congress, 58th Session.

Van Hertem, D., 2009. The use of power flow controlling devices in the liberalized market. Ph.D. dissertation, Katholieke Universiteit Leuven.

Van Hertem, D., Verboomen, J., Belmans, R., Kling, W., 2005. Power flow control devices: an overview of their working principles and their application range. In: Proceedings of the International Conference on Future Power Systems, Amsterdam, the Netherlands.

Zhang, X.-P., Yao, L., Chong, B., Sasse, C., Godfrey, K.R., 2005. FACTS and HVDC technologies for the development of future power systems. In: Proceedings of the International Conference on Future Power Systems. 